\title{
SUBJETIVIDADES EN ARTE CONTEMPORÁNEO: LO PROSCRITOY LO UTÓPICO
}

\author{
Subjetividades em arte contemporânea: o proscrito e o utópico \\ Subjectivities in contemporary art: the outlaw and the utopian
}

Rosa Maria Blanca ${ }^{1}$

\begin{abstract}
Resumen
El presente artículo posee como objetivo principal discutir la subjetividad como una dimensión de la pesquisa en artes visuales, problematizando la identidad de género, la identidad nacional y otras clasificaciones, en la cultura y en un contexto local y global. La demanda de los estudios de subjetividades es una consecuencia de los distintos desplazamientos territoriales y conceptuales en el mapa del arte contemporáneo. Se sugiere que existen determinadas prácticas artísticas que cuestionan saberes y dicotomías y que, debido a la forma en que actúan, colaboran para la (re)actualización del sistema de las artes. Se propone la espacialidad, la identidad y la extranjeridad, como conceptos operacionales en la investigación y también, como fenómenos que repercuten en las formas de acción en la contemporaneidad. Son analizados los proyectos de investigación: Tránsitos (des)identitarios: arte como proceso de subjetivación y, Arte desde los márgenes: extranjeridades y (des) localizaciones, de autoría propia.
\end{abstract}

Palabras-clave: Arte contemporáneo. Extranjeridades. Identidades. Sistema de artes. Estudios de subjetividades.

\section{Resumo}

O objetivo principal do presente artigo é discutir a subjetividade como uma dimensão da pesquisa em artes visuais, problematizando a identidade de gênero, a identidade nacional e outras classificações, na cultura e em um contexto local e global. A demanda crescente nos estudos de subjetividades é uma consequência dos diferentes deslocamentos territoriais e conceituais no mapa da arte contemporânea. Sugere-se que existem determinadas práticas artísticas que questionam saberes e dicotomias e que, pela sua forma de agirem, colaboram para a (re)atualização do sistema das artes. Propõe-se a espacialidade, a identidade e a estrangeiridade como conceitos operacionais na pesquisa e, também, como fenômenos que afetam as formas de ação na contemporaneidade. Analisam-se os projetos de pesquisa: Trânsitos (des)identitários: arte como processo de subjetivação e, Arte nas margens: estrangeiridades e (des)localizações, de autoria própria.

Palavras-chave: Arte contemporânea. Estrangeiridades. Identidades. Sistema das artes. Estudos de subjetividades 


\begin{abstract}
The main objective of this article is to discuss subjectivity as a dimension of visual arts, problematizing gender identity, national identity and other classifications in the art system, in culture and in a local and global context. The increasing demand in the studies of subjectivities is a consequence of the different territorial and conceptual displacements in the map of the contemporary art. It is suggested that there are certain artistic practices that question knowledge and dichotomies, and collaborate to (re) update the arts system. Spatiality, identity and foreignness are proposed as operational concepts in research, and also as phenomena that affect contemporary forms of action. The research projects are analyzed: Transits and (dis) identity: art as process of subjectivation ,and Art in the margins: foreign and (dis) locations, of own authorship.
\end{abstract}

Keywords: Contemporary art. Foreign affairs. Identities. Subjectivity studies. System of arts

Investigar arte contemporáneo como paradigma es un desafío epistemológico, estético, poético y político. Los distintos pensamientos y praxis que atraviesan sus filosofías, saberes y acciones resignifican modos distintos de entender y hacer arte en un contexto de mundialización. La creciente demanda de los estudios de subjetividades, dados las últimos cuestionamientos y deconstrucciones de sí y del (la) Otro(a), torna la investigación complexa y su escritura vulnerable. Esos desacomodos en los saberes y acciones constituyen preocupaciones del presente escrito.

Contradicciones, desavenencias y discrepancias, habitan en el lenguaje del arte y de la escritura. El pensamiento que está siendo propuesto, escrito, en este texto, está habitado por el desastre de lo que no puede ser dicho (BLANCHOT, 1990). Parece imposible disociar la práctica mental de distintas percepciones, acciones, viajes y acontecimientos de sí, contigo, con nosotros(as), con vosotros(as) y con ellos(as). Se entiende la escritura como un ejercicio del cuerpo y las imágenes como una proyección inédita de gestos - evidentes - y donde además, ambas formas de expresión constituyen el lenguaje autoral. Porque "(...) sin lenguaje, nada se muestra" (BLANCHOT, 1990, p. 17).

Quien se encuentra en condición de migrante, como yo, es común que se depare con extrañamientos constantes debido a los infinitos desplazamientos y situaciones en movimiento. Es decir, propongo al desplazamiento y a la extranjeridad como modos de producción de conocimiento. Una solución para poder cotejar y activar la sensación de extranjeridad ha sido la de actuar en diferentes interfaces para poder dar continuidad a procesos de subjetivación específicos, a la necesidad de (inter)acción. Esas interfaces son los proyectos curatoriales, las curadurías de exposiciones, la elaboración y exposición de trabajos artísticos, la escritura y reflexión de esas curadurías y/o de obras de arte, las clases en la graduación y en el posgrado y, finalmente, las conferencias en seminarios, congresos, encuentros o simposios. La práctica y la teoría se tornan híbridas en el arte contemporáneo (COËLLIER, 2016).

Todas esas actuaciones son consideradas como un único trabajo de investigación, tanto teórico, cuanto práctico, porque parten de un mismo proyecto de búsqueda. Es a lo que denomino conceitualización. Las distintas experimentaciones constituyen reverberaciones de una misma idea y, son implicaciones o consecuencias del contexto actual en el campo del arte. También es una tentativa de constituir actividades productivas - teóricas y artísticas - como un medio de expansión humana (GORZ, 2005).

Los cuestionamientos culturales inducen a una interacción de los afectos. Los proyectos curatoriales, las exposiciones, las fotografías, los dibujos y el presente escrito, son procesos de constitución de sí, tanto teóricos, cuanto prácticos, tanto subjetivos, cuanto políticos.

En ese sentido, se considera que la producción de investigación en subjetividades, se inserta en el paradigma del arte contemporáneo en un contexto de tránsito, debido precisamente al proceso de extranjerización en el que vivo.

Es así cómo el presente artículo posee como objetivo principal discutir dos proyectos de investigación intitulados: a) Tránsitos (des)identitarios: arte como proceso de subjetivación y, b) Arte desde los márgenes: extranjeridades y (des)localizaciones, los cuales problematizan las identidades y las subjetividades en el arte contemporáneo. Ambos proyectos han surgido y están siendo desarrollados en el Laboratorio de Arte y Subjetividades (LASUB), núcleo de investigación creado el 27 de mayo de 2015, en el ámbito del Programa de Posgrado en Artes Visuales (PPGART) de la Universidad Federal de Santa Maria, Brasil.

Sin lugar a dudas, los proyectos a tratar son consecuentes de las investigaciones que han sido efectuadas durante la Maestría en Artes Visuales - UFRGS - (BLANCA, 1999) y en el Doctorado Interdisciplinar en Ciencias Humanas - UFSC (BLANCA, 2011).

\title{
Lo raro, lo monstruoso y lo disonante
}

En lo que se refiere al proyecto Tránsitos (des)identitarios: arte como proceso de subjetivación, investigo cómo la subjetividad interfiere en la constitución de sí en el sujeto artista. Utilizo los museum studies/estudios de museos y la feminist museology/museología feminista, con la finalidad de experimentar otros procesos de configuración de las muestras de arte. Estoy entendiendo la exposición como una forma de producción de conocimiento y donde los estudios de museos actúan 
inter y transdisciplinariamente, cuestionando saberes y discursividades hegemónicas, oriundos de áreas de conocimiento y disciplinas científicas.

Así, he realizado proyectos curatoriales para la $I^{2}$ y II Exposición Internacional de Arte y Género ${ }^{3}$, instaladas en el Museu de Arqueologia e Etnologia, Florianópolis, Brasil, y para la muestra Tránsitos (Des)Identitários ${ }^{4}$, en la Sala Cláudio Carriconde, UFSM, Brasil, donde los procesos de subjetivación de los(as) artistas producen estéticas que no se enfocan en una imagen fija o binaria de la estética de género. La idea es proponer visualidades de identidades que todavía no existen o que pueden llegar a existir o simplemente, bocetar subjetividades que escapan de la norma de género (BUTLER, 1990). Los(as) artistas que participan en las exposiciones producen una espacialidad donde el (la) espectador (a) puede realizar reflexiones sobre sí mismo (a) o bien, (des)identificarse con las estéticas propuestas. Lo importante es ampliar imanentemente visiones, perspectivas y afectos.

Aunque muchas veces se hayan etiquetado estas muestras colectivas de arte y género que curo, como arte gay, arte lésbica o arte queer, es importante que se destaque que no se pretende afirmar o posicionar la exposición en términos de representatividad. No son muestras de denuncia. Se intenta dar visualidad a artistas que no pueden exponer sus trabajos en los museos. Lo acepto. Pero no se parte de categorías como inclusión, para idear la curaduría. La representatividad puede ser un resultado o una consecuencia, pero no es intencional. Se investiga cómo es posible proponer imágenes o estéticas que no se cierran en un reconocimiento, en la estabilidad visual o en la inteligibilidad de la norma (BUTLER, 1990; BLANCA, 2017), todo lo contrario. Lo que me interesa es buscar otros modos de seducción intersubjetiva a través del lenguaje del arte contemporáneo.

A partir de una una percepción queer, las obras expuestas, mediante el proyecto curatorial, generalmente desembocan en sensaciones ambiguas. Este tipo de arte interfiere en la pedagogía visual de los museos que en su génesis han colaborado para afirmar un proceso civilizatorio e higienista. En las exposiciones colectivas que efectúo, las corporalidades interactúan con el imaginario del público de tal manera que, los afectos, las subjetividades, las seducciones, pueden llegar a constituirse en una dimensión fenomenológica o estética.

En la curaduría, el espacio museográfico también es fundamental para la perspectiva subjetiva de la exposición. Intento disponer los trabajos atravesando el espacio de tal forma que, el(la) espectador(a) pueda fluir y advenir de un lugar a otro, de un trabajo a otro, asociando las obras de acuerdo a su punto de vista, pero también disociarlas y obtener percepciones singulares, tomando en cuenta la pluralidad del evento. Me interesa dejar espacios amplios. Creo en el espacio expográfico como un lugar privilegiado para la producción de un espacio y un tiempo singular y sin precedentes. La idea es que se construyan reflexiones abiertas mediante la asociación de imágenes propuestas por los(as) artistas pero que, en la exposición han sido montadas sugiriendo diálogos, contradicciones e incertidumbres.

Pienso en la exposición como un espacio de libertad.

Considero que el trabajo del (la) curador (a), más allá de configurar una mediación entre obras y público, es una propuesta de percepción del arte a partir de la espacialidad y de la temporalidad que proyecta en la exposición. El proyecto curatorial demanda el estudio del locus de la muestra, de las obras, de los artistas y del contexto cultural y estético en que se produce la exposición.

El proyecto curatorial exige la sensibilidad del autor /curador (a). Porque para simplemente exhibir las obras, para eso bastan los catálogos o las medias. La construcción del espacio espeja la propuesta del (a) curador y su propia definición de arte, desafiando el tiempo y la cultura. El recorte de las obras es un acto de enunciación. Se propone una heterotopía, un asilo políticamente conceptual a los (as) abyectos. Esa temporalidad viva modifica la percepción de su interlocutor, conduciendo a la producción de un pensamiento y una experiencia que puede contribuir a una afectividad de sí diferente a la de antes de visitar la exposición.

2 - La I Exposición Internacional de Arte y Género (2013), , bajo la curaduría de Rosa Blanca y, en el marco del Seminario Haciendo Género $10^{\circ}$, ha tenido la participación de artistas como Ale Mello, Alexandra Eckert, Alexandra Martins, Alice Monsell, Andressa Rosa, Barbara Bublitz, Cristhian Cajé, Consuelo Schilchta, Marília Diaz, Dulce Mazer, Edla Eggert, Ivone Junqueira, Elisa Riemer, Elo Veja, Fagnah Puñal, Isabel Sommer, Junior Ratts, Kethlen Kohl, Lehw Castro, Lia Jupter, Lucia Gorosito Guajardo, Luciana Martins Coelho, Lucilia Alencastro, Marcela Alvim, Manuela Venancio, Marcelo Chardosim, Milena Costa, Nadia Senna, Nizael Almeida, Stélio Constantino, Patricia Giseli, Roberta Stubs, Rosana Bortolin, Rosa Santos, RosiMeire da Silva, Sylvana Lobo e Vera Junqueira, Talita Trizoli, Tamires Schmitt e Tati Bafo. En la organización del Seminário Fazendo Gênero 10, ha sido Luzinete Simões y Cláudia de Lima Costa, quienes han colaborado para el desarrollo de la exposición. Julia Godinho ha actuado como Asistente Curatorial.

3 - La II Exposición Internacional de Arte y Género (2017), bajo la curaduría de Rosa Blanca y, en el marco del Seminario Haciendo Género 11 ○ \& Women's Worlds Congress 13th, ha tenido la participación de artistas como Agnes Vilseki, Alexandra Martins, Alice Monsell, Aline Daka, Ana Sabiá, Cheyenne Luge, Clarissa Borges, Cláudia Paim, Consuelo Schlichta, Clarissa Silva e Elisete Machado, Diane Sbardelotto, Elisa Comandulli, Heloisa Angeli, Itamara Ribeiro, Larissa Schip, Letícia Cobra Lima, Lívia Auler, Leli Baldissera, Mirela Ferraz, Nadia Senna, Natália Rosa, Rosana Bortolin, Sophia Pinheiro y Waleska Timmen. Jacks Ricardo Selistre ha actuado como Asistente Curatorial.

4 - Esta exposición de 2016, en el ámbito del Seminário de (Des)Configuraciones y Subjetivaciones en Artes, ha tenido como Asistente Curatorial a Jacks Ricardo Selistre, y como Assistentes de Curadoría Artística a Letícia Honorio y Ana Eliza Belizário. Participaron los(as) artistas: Andreia Oliveira, Cheyenne Luge, Jacks Ricardo Selistre, Letícia Honorio, Lutiere Dalla Valle, Marcelo Chardosim, Marilia Jeffman, Rafael Durante, Rafael Falk, Rosa Blanca, Virgínia Villaplana Ruíz y William Silva. 


\section{Lo apátrida, lo sin espacio y lo sin tiempo}

En el proyecto Arte desde los márgenes: extranjeridades y (des)localizaciones ${ }^{5}$, investigo los extrañamientos artísticos que surgen en la frontera. En ese sentido, también me interesan las muestras de arte que se producen en un contexto inter o transnacional. En estas exposiciones, deseo construir propuestas curatoriales que cuestionen lo territorial o lo nacional.

Este tipo de cuestionamientos han estado presentes en exposiciones del arte contemporáneo en su historia reciente. Puede ser recordada la $8^{a}$ Bienal de Sharjah: Arte, ecología y políticas de cambio (2007), insertada en un ámbito posnacional y poshistórico, de movilidad y de mudanzas identitarias (MORATÓ, 2011).

Otra muestra que dibuja una cartografía (des)identitaria en el contexto internacional ha sido la última Documenta de Atenas - Kassel (2017), donde uno de los curadores, el filósofo trans Paul B. Preciado, ha presentado a los(as) artistas sin referenciarlos de acuerdo a su nacionalidad. Al desconsiderar el "origen" de los(as) artistas, el espectador(a) se ha deparado con obras (des)localizadas, contribuyendo para la interacción activa hacia a una comprensión estética pos-identitaria. Bajo el concepto de muestra "apátrida", Preciado (2017) deslegitima la autoridad de la patria y del Estado-nación en el contexto actual de flujos migratorios, proponiendo el arte contemporáneo como una heterotopía para refugiados y para todos(as) aquellos(as) sujetos desclasificados y(o) ininteligibles.

Me parece que la clasificación continental o nacional en el arte, como arte europea, arte americana, arte africana, arte asiática, arte latinoamericana, arte española, arte aborigen australiana o arte brasileña, etc, etc, doctrina a la creatividad, a la imaginación, al pensamiento y al entendimiento de lo estético y de lo subjetivo.

De esa forma, intento (des)localizar en las muestras, donde actúo como curadora, el trabajo de los(as) artistas. En la exposición internacional Fronteras - Referencias Cruzadas $^{6}$, montada en el Centro de Convenciones de la Universidad Federal de Santa Maria, Brasil, por ejemplo, he percibido que la gran mayoría de las obras han sido pinturas, grabados o dibujos en rollos larguísimos de papel, a la manera de pergaminos. He suspendido esos pergaminos en el espacio expográfico para sugerir cartografías intersubjetivas, ya que los territorios han proyectado topografías imaginarias. Aunque en esta exposición han estado participando artistas de Argentina, Brasil, México y Uruguay, la (in)definición de los mapas ha visualizado las cartas hipotéticamente de la América del Sur como dibujos y ficciones, en sus más variadas (des)coordenadas geográficas.

Un acontecimiento que llama la atención, en esta muestra, ha sido el hecho de que una artista, Mabel Larrechart, que ha estado participando por México ha nacido en Argentina. Y yo que he participado por parte del grupo de Brasil, he nacido en México. A eso también me refiero como extranjeridades en el arte.

Aunque se diga que la globalización ha homogeneizado el arte, el protocolo formal y estético de quien produce o actúa se ve constantemente cuestionado. Existen varias praxis locales que se naturalizan y se justifican en el campo. La investigación en Brasil, por ejemplo, ha llevado a la constitución de organizaciones y asociaciones que marcan el papel de sus agentes.

Esa praxis local/nacional tensiona la producción artística en desplazamiento. El extrañamiento es evidente. Los(as) actores, como docentes, investigadores, artistas, historiadores y (o) críticos, luchan para (re)marcar lo diferente, estableciendo o reposicionando papeles predefinidos a quien proviene del extranjero.

Así como se instituye una identidad de género o una identidad nacional, igualmente se determinan identidades con papeles o comportamientos predeterminados en el arte, en sus funciones y ocupaciones. La destinación opera en distintos niveles. Se inventan colectivos de enunciación apropiándose de los cuerpos, gestos y ritmos de trabajo, pero también de las formas de percepción.

La investigación que estoy proponiendo, en este contexto, problematiza la constitución de esas identidades, discutiendo los procesos de subjetivación que repercuten en la gestión de la percepción, tanto artística, cuanto estética.

La condición de migrante, como flujo, movimiento y actitud nómada, produce procesos de extranjerización en el arte, algunos vulnerables, otros en resistencia. La extranjeridad me permite sentir el espacio, el tiempo y la determinación de las funciones en el campo, en una dimensión aleatoria, incidiendo en mis gestos, ritmos y decisiones. Es así como emerge mi poética, como artista, actualmente. El modo en que me narro determina mi lenguaje, los materiales, el dispositivo y la técnica de producción, sugiriendo otra subjetividad en mi práctica artística, otra de las interfaces en las que actúo.

5 Una versión de esta investigación ha sido presentada como comunicación intitulada Entre los márgenes y lo global: intersubjetividades y (des)localizaciones, en el $1{ }^{\circ}$ Simpósio Internacional de Relações Sistêmicas da Arte - Arte Além da Arte, 08 a 10 de abril de 2018 , Goethe-Institut, Porto Alegre, bajo la coordinación de Maria Amélia Bulhões y organizada por Bruna Fetter y Nei Vargas.

6 En esta exposición, bajo la curaduría de Rosa Blanca, han participado artistas como Carlos Coppa, Domingo Alagia, Eric Markowski, Juan Pablo Martín, Leticia Barbeito, María Alvardo, María Paula Obiña, María Sanquinetti, Mariana Soibelzon, Yamila Vilalba, Andréia Oliveira, Altamir Moreira, Helga Correa, Karine Perez, Lutiere Dalla Valle, Rebeca Stumm, Reinilda Minuzzi, Rosa Blanca, Álex Bolio, Ernesto Alva, Aminta Espinoza, José Porras, Mabel Larrechart, Mike Gómez, Oscar Padilla, Rubén Morales, Sofía Echeverri, Verónica Bapé, Fernando Miranda, Gonzalo Vicci, Karina Perdomo, Marcela Blanco, Micaela Fernández y Yohnattan Mignot. La muestra ha sido organizada por Lutiere Dalla Valle, Carlos Coppa, Mabel Larrechart y Fernando Miranda, ha contado con el apoyo del Programa de Posgrado en Artes Visuales (PPGART) y del Curso de Graduación en Artes Visuales (CAV) de la Universidade Federal de Santa Maria, de la Universidad de la República de Uruguay y de la Universidad Nacional de la Plata. Han participado en la Comisión de Organización: Ana Elisa Belizário, William Silva, Jacks Ricardo Selistre y Denise Losekan, del Laboratorio de Arte y Subjetividades (LASUB/UFSM). La exposición ha tenido lugar en el Centro de Convenciones de la Universidad Federal de Santa Maria, en Santa Maria, Brasil, en Octubre de 2017. 
La serie que he producido No me peguen (2017) ${ }^{7}$ incluye autorretratos en fotografía y dibujo. Se sugiere la (des)marcación mediante el movimiento frente a la cámara fotográfica. Hay una tentativa de desacomodo frente a la nitidez clásica del retrato. Los documentos de identidad prevén la retención del rostro. El (im)pulso mientras me retrato produce una estética borrada. Sin huir, interfiero en el registro.

En los dibujos, transfiero esa necesidad de expresarme a mí misma con mis propios trazos. Mi acción está presente en cada línea designada sin (pre)visión sobre el papel, sensiblemente fragilizada.

\section{Proyectos en proceso - a modo de conclusión}

Aparentemente, parece que los proyectos de investigación que han sido discutidos son diferentes. No lo son. Ambos problematizan las identidades y sugieren extranjeridades, espacialidades y temporalidades, territorios heterotópicos. Según explica Paolo Zanotti (2010), cuando habla de nuevos imaginarios y nuevas patrias, existen geografías que cuando distantes, parecen ser en general lugares privilegiados para la imaginación gay, para los abyectos o los sin identidad - inteligible -. Cómo es el caso del Mediterráneo, donde apasionadamente, escritores, artistas, intelectuales y otros perseguidos(as) acostumbraban en el pasado habitar sus imaginaciones (2010).

Parece que con la intensificación de lo real, bajo el control geopolítico, no existen ni nuevos imaginarios y ni nuevas patrias.

Han sido las exposiciones, las imágenes, los poemas, los graffities y otras espacialidades, las que realmente se han constituido como fronteras, lugares de extranjeridades o verdaderas heterotopías de lo impropio, de lo perseguido y de lo (des)clasificado. Probablemente sea ese el motivo por haber tantas muestras, filmes y pintas censuradas.

Lo marginal, lo anacrónico, lo extraño, lo que no lleva nombre, lo que probablemente existe o existirá, habita y habitará eternamente en el arte, contemporáneo.

\section{Referencias}

BLANCA, Rosa Maria. A crise da identidade nacional no território mediado. 1999. Dissertação (Mestrado em Artes Visuais) - Universidade Federal do Rio Grande do Sul. Programa de Pós-Graduação Interdisciplinar em Ciências Humanas. Instituto de Artes, Porto Alegre, 1999. Orientación: Maria Amélia Bulhões.

BLANCA, Rosa Maria. Arte a partir de uma perspectiva queer / Arte desde lo queer. Tese bilíngue de Doutorado, Programa de Pós-Graduação Interdisciplinar em Ciências Humanas. Orientação: Miriam Pillar Grossi; Coorientação: Cláudia de Lima Costa. Centro de Filosofia e Ciências Humanas, Universidade Federal de Santa Catarina, Florianópolis, 2011.

BLANCA, Rosa Maria. Exposições queer: contextos mundiais e locais. Cadernos de Gênero e Diversidade. 3 (3), p. 93 107, 2017. Disponível em: https://portalseer.ufba.br/index.php/cadgendiv

BLANCHOT, Maurice. La escritura del desastre. Caracas: Monte Ávila Editores, 1990.

BUTLER, Judith. Gender Trouble. Feminism and the subversion of identity. New York / London: Routledge, 1990.

COËLLIER, Sylvie. Artiste, chercheur, curateur: des roles en négociations. Revue Proteus. Vol. 10, p. 7 - 18, 2016.

GORZ, André. Crise e êxodo da sociedade salarial. Cadernos IHU Ideias. Ano 03, No 31, 2005. Disponible en: <http:// www.ihu.unisinos.br/images/stories/cadernos/ideias/031cadernosihuideias.pdf> Acceso el: 14 Marzo 2018.

HEINICH, Nathalie. Práticas da arte contemporânea: uma abordagem pragmática a um novo paradigma artístico. Sociologia \& Antropologia. Rio de Janeiro, v. 4, n.2, 02, p. 373 - 390, Outubro 2014. Disponível em: <http://www. scielo.br/pdf/sant/v4n2/2238-3875-sant-04-02-0373.pdf> Acceso el: 21 Marzo 2018.

MORATÓ, Ma Elena. Arte y crítica: otras realidades, otros objetivos, para la reflexión social. Quaderns de la

7 - Este trabajo lo he mostrado como proyección en la exposición colectiva PPGART = Arte + Pesquisa, Sala Cláudio Carriconde, Santa Maria, 03 - 20 de Octubre de 2017, donde han participado otros(as) artistas como Rebeca Stumm, Helga Correa, Karine Perez, Lutiere Dalla Valle, Altamir Moreira, Gisela Biancalana, Reinilda Minuzzi, Andrea Oliveira e Raquel Fonseca, bajo la curadoría de Nara Cristina Santos. La expografía ha estado a cargo de Cristina Landerdahl y Rittiele Quaiatto. Esta exposición ha acontecido de maneira simultánea con la muestra Fronteras: Referencias Cruzadas, Centro de Convenciones, Universidad Federal de Santa Maria, Santa Maria, donde he expuesto una versión en dibujo de No me peguen (2017). 
Mediterrània. N. 15, p. 253 - 256, 2011.

PRECIADO, Paul B. La exposición apátrida. Babelia. EL PAIS. 8 abril 2017. Disponible en: <https://elpais.com/ cultura/2017/04/05/babelia/1491405260_376869.html>. Acceso el: 19 Mayo 2017.

ZANOTTI, Paolo. Gay. La identidad homosexual de Platón a Marlene Dietrich. México: Fondo de Cultura Económica Turner, 2010. 